\title{
The Effect of Longitudinal Stretching of Muscles and Nerve versus Deep Transverse Friction Massage in the Management of Patients with Carpal Tunnel Syndrome
}

\author{
Ashraf Ramadan Hafez ${ }^{1 *}$, Aqeel Mohammed Alenazi², Shaji John Kachanathu3, \\ Abdulmohsen Meshari Alroumi4 ${ }^{4}$, Elham Saed Mohamed ${ }^{5}$ \\ ${ }^{1}$ Cairo University Hospital, Cairo University, Cairo, Egypt \\ ${ }^{2}$ Physical Therapy and Rehabilitation Department, College of Applied Medical Sciences, Salman Bin Abdulaziz \\ University, Alkharj, Saudi Arabia \\ ${ }^{3}$ Collage of Applied Medical Sciences, King Saud University, Riyadh, Saudi Arabia \\ ${ }^{4}$ Physical Therapy Department, College of Applied Medical Sciences, Shaqra University, Shaqra, Saudi Arabia \\ ${ }^{5}$ Cairo University Hospital, Cairo University, Cairo, Egypt \\ Email: ${ }^{*}$ ashrafrh1989@yahoo.com
}

Received 20 August 2014; revised 23 September 2014; accepted 22 October 2014

Copyright (C) 2014 by authors and Scientific Research Publishing Inc.

This work is licensed under the Creative Commons Attribution International License (CC BY).

http://creativecommons.org/licenses/by/4.0/

(c) $\underset{\mathrm{EY}}{\mathrm{E}}$ Open Access

\section{Abstract}

Background and Purpose: Carpal tunnel syndrome (CTS) is a common source of hand numbness and pain. The goal of this study was to compare longitudinal stretching of muscles and nerve to deep transverse friction massage for decreasing pain and improving hand function in patients with chronic CTS. Subjects and Methods: Thirty patients, 25 to 40 years old, were included in this study and randomized into two groups: the first group $(36.8 \pm 0.262)$ followed a physical therapy program group receiving stretching of wrist and hand flexors in combination with ultrasound, strengthening exercises of wrist and hand flexors, and wrist splint, three sessions per week for 12 weeks; and the second group $(35.9 \pm 0.225)$ followed the physical therapy program of deep transverse friction massage on the carpal tunnel site at the wrist joint, with using ultrasonic therapy, strengthening exercises of wrist and hand flexors and wrist splint, three sessions per week for 12 weeks. Outcome measures were range of motion (ROM), pain using visual analog scale (VAS), and hand grip strength measured with a sphygmomanometer. Results: There was a significant difference in both groups in all outcome measures compared to baseline. Over stretching group showed significant difference at the end of study in terms of range of motion of wrist flexion, extension and strength of handgrip when compared to deep friction massage group $P<0.05$. However, there is no significant difference between groups in pain. Discussion and Conclusion: This study showed

\footnotetext{
${ }^{*}$ Corresponding author.
}

How to cite this paper: Hafez, A.R., et al. (2014) The Effect of Longitudinal Stretching of Muscles and Nerve versus Deep Transverse Friction Massage in the Management of Patients with Carpal Tunnel Syndrome. Open Journal of Therapy and Rehabilitation, 2, 199-206. http://dx.doi.org/10.4236/ojtr.2014.24025 
that the effect of stretching exercises is more beneficial than deep transverse friction massage in the treatment of patients with CTS in decreasing the compression of the median nerve in the tunnel.

\author{
Keywords \\ Carpal Tunnel Syndrome, Median Nerve, Stretching Exercises, Ultrasonic Therapy, Deep \\ Transversefriction Massage, Hand Weakness And Numbness
}

\title{
1. Introduction
}

Carpal tunnel syndrome (CTS) is the most common neuropathy that results from compression of the median nerve, and increasing the volume of structures or decreasing the space inside the tunnel can cause the symptoms. Nine flexor tendons and one nerve, the median nerve pass through the tunnel between the tendons of flexor digitorum profondus and flexor digitorum superficialis. The carpal bones form the carpal tunnel dorsal surface and the transverse carpal ligament forms the volar surface of the tunnel. The location of median nerve inside the tunnel is superficial to the superficial flexor tendon of the ring and middle fingers [1] [2].

Carpal tunnel syndrome mainly affects women in the middle age. The exact etiology and pathogenesis of CTS is unclear in the majority of patients. The evidence is not clear about linking several occupations with the incidence and prevalence of CTS [3]. Carpal tunnel syndrome diagnosis is based on patient's clinical, history, physical examination and is confirmed by electrophysiological studies [4]. One in five symptomatic patients expected to be diagnosed with carpal tunnel syndrome based on clinical examinations and electrophysiological studies [5] [6].

Diagnostic methods of CTS include the electrophysiological study (nerve conduction study [NCS]), Magnetic Resonance Imaging (MRI) and ultrasonography. The diagnostic physical examinations for the CTS are the Phalen test (PT), hand elevation test (HET), and Tinel sign (TS). Among these physical examinations, PT and HET have been reported in the literature to be highly correlated with the electrophysiological diagnosis of CTS [7] [8].

Medical or surgical interventions have been reported for the treatment of CTS. Recent studies have shown that steroid injection is an appropriate treatment in carefully selected patients [9]. In addition, steroid injection is an effective and safe option of treatment; the benefit of steroid injection after 8 weeks has not been demonstrated [10] [11]. In a systematic review, 12 trials have been evaluated, including two randomized control trials, and have concluded that steroid injections have greater improvement in symptoms than placebo at only one month follow-up [10]. Also, there is no consensus regarding the repetition of the injections. Studies recommended no more than one injection per six months in the wrist [12].

High-quality evidence has revealed that treatment options for CTS consist of corticosteroid injection for mild to moderate conditions [10] [13] and surgical decompression in moderate to severe cases [13]. Surgical procedure for CTS involves division of the flexor retinaculum and nerve release. This can be done through traditional open decompression surgery or mini incision techniques [6] [14] [15]. Limited evidence has compared the surgical intervention to splinting. In the systematic review in 2008, only two randomized trials were identified that compared surgical intervention to splinting and none of them have blinded assessment of outcomes [16]. Some surgical complications occur including inadequate division of the transverse carpal ligament, injuries and lacerations of the median nerve and branches, vascular injuries, wound infections and complex regional pain [17] [18]. So, many interventional options should be considered before surgery.

Conservative treatment including using of splinting, modalities such as ultrasound, phonophoresis, and iontophoresis may provide relief in some patients. Interestingly, it can enlarge the carpal tunnel by specific stretching techniques. Such an exercise program may provide a noninvasive intervention for CTS. Specific stretching and strengthening programs for the hand and wrist may be useful in improving strength and dexterity particularly following surgical treatment, although it can decrease symptoms. Massage of forearm and/or nerve glide techniques offer no proven benefits [19]-[22].

The common conservative treatment of CTS is splinting of the wrist and hand, which is based on the premise that reduced movement of the carpal tunnel content and the rest facilitates resolution of inflammation. The mechanism and splinting effects are arguable and it is not clear whether the beneficial effects that occurred in such 
patients are because of movement reduction of the tunnel contents or reduction in intra-tunnel [23]-[27].

The aim of this study was to compare the effect between longitudinal stretching of muscles and nerve and deep transverse friction massage in the treatment of patients with carpal tunnel syndrome.

\section{Materials and Methods}

\subsection{Subjects}

This study was approved by Research Ethics Committee at Cairo University Hospital and all participants signed informed consent forms, and were informed about the whole procedures before testing and training. All patients were recruited from outpatient clinic of orthopedic departments at Cairo University hospitals.

Many patients were assessed to determine their eligibility, age, and diagnosis. Inclusion criteria were as follows; patients with carpal tunnel syndrome diagnosis. Exclusion criteria were as follows; previous history of surgery to carpal tunnel, diabetes or peripheral neuropathy. This study included 30 males and females volunteer patients divided randomly into two groups, the first group followed a physical therapy program of exercise in the form of stretching of wrist and hand flexors with using ultrasonic therapy, strengthening exercises of wrist and hand flexors and wrist splint, three sessions per week for 12 weeks (mean age $=36.8$, SD \pm 0.262 years), the second group followed a physical therapy program of deep transverse friction massage on the carpal tunnel site at the wrist joint, with using ultrasonic therapy, strengthening exercises of wrist and hand flexors and wrist splint, three sessions per week for 12 weeks (mean age $=35.9$, SD $=0.225$ years). All of them were suffering from pain, limitation of range of motion (ROM) of wrist extension and flexion, and handgrip.

\subsection{Evaluation Procedures}

Universal goniometer was used to measure the range of motion (ROM) of wrist extension and flexion [28]. Visual analogue scale (VAS) was used to measure the pain severity [29]. Finally, Squeezing sphygmomanometer was used to test the strength of handgrip [30].

\subsection{Treatment Procedures}

The first group followed a physical therapy program of: 1) exercise in the form of longitudinal stretching of muscles of wrist and hand flexors (three repetitions, 30 seconds in position of stretching, 30 seconds in position of relaxation with elbow extended with five sets) [31]; 2) ultrasonic therapy [19] (5 minutes, 2 w/sec ${ }^{2}$ in continuous form); 3) strengthening exercises of wrist and hand flexors (minimal resistive exercises, 10 repetitions for every exercise, 3 sets, 6 sec rest between each repetition, and 1 minute rest between the sets. The resistance is progressed according to repetitions) [32] and 4) wrist splint (day and night) [33], three sessions per 6 weeks.

The second group, followed the physical therapy program of 1) deep transverse friction massage on the carpal tunnel site at the wrist joint (5 minutes, by the thumb of therapist in position of extension and press during massage); 2) ultrasonic therapy (5 minutes, $2 \mathrm{w} / \mathrm{sec}^{2}$ in continuous form) [19]; 3) strengthening exercises of wrist and hand flexors (minimal resistive exercises, 10 repetitions for every exercise, 3 sets, 6 seconds rest between each repetition, and 1 minute rest between the sets. The resistance is progressed according to repetitions) [32] and 4) wrist splint (day and night) [33], three sessions per 6 weeks.

\subsection{Assessment Procedures}

All patients were assessed before treatment and reassessed after 6 weeks by using universal goniometer to measure ROM of wrist extension and flexion [28]. The fixed arm of the Universal goniometer is placed in parallel to the forearm and the movable arm in parallel to the ulnar side of the hand and little finger in 0 position then the subjects were asked to flex and extend the wrist and record the angle of flexion and extension.

Visual analogue scale was used to measure the pain [29], which is represented from (0) position to (10) position. Zero position means no pain, (10) position means unbearable pain, from 1 to 10 means gradual increasing in pain intensity. The subjects were asked to indicate the level of pain by placing a dash at the appropriate level on the $10 \mathrm{~cm}$ horizontal line.

Squeezing sphygmomanometer was used in this study to measure the power of hand grip as following [30]: instruct the patient to squeeze the cuff of the sphygmomanometer as much as possible then record the change of 
pressure pre and post the program.

\subsection{Data Analysis}

The collected data were statistically treated by using SPSS software (Statistical Package for the Social Sciences), version 18.0, SPSS Inc. Chicago, IL, USA, and the following values were found minimum, maximum, mean, S.D., one sample paired $t$-test to compare between pre and post assessment in the group. The unpaired $t$-test was used to compare pre and post assessment between two groups, at a confidence level of $(P \leq 0.05)$.

\section{Results}

There was no statistically significant difference between both groups at baseline measurements in terms of ROM of wrist flexion, extension and handgrip strength. Table 1 showed patients' pre and posttest values of pain, wrist ROM, and handgrip strength for stretching group. Table 2 showed patients' pre and posttest values of pain, wrist ROM, and handgrip strength for deep friction massage group.

Comparison between both groups, there was a significant difference in both groups in all outcome measures compared to baseline $P \leq 0.05$. Over stretching group showed significant difference at the end of study in terms of range of motion of wrist flexion, extension and strength of handgrip when compared to deep friction massage group $P \leq 0.05$. However, there is no significant difference between groups in pain. $T$-value of ROM of wrist flexion was 0.03 , $t$-value of ROM of wrist extension was 0.035 , and $t$-value of hand grip 0.02 , but no significant difference in pain, where $t$-value of pain 0.8 Table 3.

\section{Discussion}

The results of this study showed that there was a significant improvement of pain, ROM of wrist flexion and extension, and hand grip in stretching group due to use exercise program that includes, nerve and tendon gliding exercise (stretching exercise), ultrasonic therapy, wrist splint, and strengthening exercises.

Table 1. Pre and post values of pain, ROM of wrist flexion, extension, and handgrip power, in overstretching group.

\begin{tabular}{cccccccccc}
\hline & \multicolumn{2}{c}{ Pain } & \multicolumn{2}{c}{ Flexion ROM } & \multicolumn{2}{c}{ Extension ROM } & \multicolumn{2}{c}{ Handgrip Power } \\
& Pre & Post & Pre & Post & Pre & Post & Pre & Post \\
\hline Min & 7 & 3 & 40 & 63 & 23 & 45 & 20 & 40 \\
Max & 9 & 5 & 55 & 74 & 40 & 65 & 35 & 55 \\
Mean & 7.25 & 3.9 & 47.6 & 69.25 & 36.4 & 56.33 & 28.7 & 49.2 \\
SD \pm & 0.685 & 0.876 & 5.365 & 3.334 & 6.634 & 4.238 & 3.88 & 5.99 \\
T-Test & $0.004^{*}$ & & $0.007^{*}$ & & $0.005^{*}$ & & $0.02^{*}$ &
\end{tabular}

$\left(^{*}\right)$ Significant, $P \leq 0.05 ;\left(^{* *}\right)$ Non-significant, $P \geq 0.05$.

Table 2. Pre and post values of pain, ROM of wrist flexion, extension, and handgrip power, in deep friction massage group.

\begin{tabular}{|c|c|c|c|c|c|c|c|c|}
\hline & \multicolumn{2}{|c|}{ Pain } & \multicolumn{2}{|c|}{ Flexion ROM } & \multicolumn{2}{|c|}{ Extension ROM } & \multicolumn{2}{|c|}{ Handgrip Power } \\
\hline & Pre & Post & Pre & Post & Pre & Post & Pre & Post \\
\hline Min & 6 & 4 & 40 & 45 & 20 & 30 & 15 & 20 \\
\hline Max & 9 & 7 & 55 & 65 & 45 & 56 & 30 & 35 \\
\hline Mean & 7.8 & 5.9 & 48.6 & 53.9 & 36.5 & 44.6 & 26.9 & 27.6 \\
\hline $\mathrm{SD} \pm$ & 0.71 & 0.8 & 3.564 & 2.89 & 4.25 & 3.88 & 3.78 & 3.98 \\
\hline T-Test & $0.02^{*}$ & & $0.01^{*}$ & & $0.01^{*}$ & & $0.58^{* *}$ & \\
\hline
\end{tabular}

( ) Significant, $P \leq 0.05 ;\left(^{* *}\right)$ Non-significant, $P \geq 0.05$. 
Table 3. The mean values of posttest of pain, ROM of wrist flexion, ROM extension, and handgrip power in both groups.

\begin{tabular}{ccccccccc}
\hline & \multicolumn{2}{c}{ Pain } & \multicolumn{2}{c}{ Flexion ROM } & \multicolumn{2}{c}{ Extension ROM } & \multicolumn{2}{c}{ Handgrip Power } \\
\hline & $1^{\text {st }}$ gr. & $2^{\text {nd }}$ gr. & $1^{\text {st }}$ gr. & $2^{\text {nd }}$ gr. & $1^{\text {st }}$ gr. & $2^{\text {nd }}$ gr. & $1^{\text {st }}$ gr. & $2^{\text {nd }}$ gr. \\
\hline Min & 3 & 4 & 63 & 45 & 45 & 30 & 40 & 20 \\
Max & 5 & 7 & 74 & 65 & 65 & 56 & 55 & 35 \\
Mean & 3.9 & 5.9 & 69.25 & 53.9 & 56.33 & 44.6 & 49.2 & 27.6 \\
SD \pm & 0.876 & 0.8 & 3.334 & 2.89 & 4.238 & 3.88 & 5.99 & 3.98 \\
T-Test & 0.8 & & 0.03 & & 0.035 & & 0.02 & \\
\hline
\end{tabular}

$\left(^{*}\right)$ Significant, $P \leq 0.05 ;\left(^{* *}\right)$ Non-significant, $P \geq 0.05$.

The longitudinal stretching of muscles and nerve is based on the principle of improving the movement of peripheral nerves and releasing compression through longitudinal stretching of the muscles and nerves. If there is inability to move nerves, the symptoms may be occurred due to loss of nerve movement. At the wrist, as in most body areas, a normal longitudinal movement is required (glide and stretch). Flexion of the digits causes sliding of the median nerve proximally into the forearm; with finger extension, sliding of the median nerve occurred distally towards the hand [5]. Hyperextension of the wrist and fingers causes displacement of the median nerve to farthest beneath the transverse carpal ligament into the hand (10 - $15 \mathrm{~mm}$ relative to a fixed bony landmark in the carpal tunnel). During flexion of wrist and fingers, there is a displacement of median nerve two to four times greater at the wrist than in the upper arm. The median nerve should slide during movement instead of being stretched continuously. In the carpal tunnel, there should be a normal movement relationship between the median nerve and the tendons of flexor muscles. Stretching exercise also reduces spasm of the muscles and improves blood circulation, which decreases the metabolites concentration to relief the pain [34]-[37].

One of the major effects of using ultrasound therapy is softening the hard tissues around the muscles and nerves through its micro massage effect. The efficacy of using low intensity ultrasound thermotherapy was satisfied and more effective for mild to moderate Carpal tunnel syndrome cases [38] [39].

In deep transverse friction massage group, there was a significant improvement of pain, ROM of wrist flexion and extension due to using of deep friction massage, which modulates of the nociceptive impulses at the level of the spinal cord: the "gate control theory". The centripetal projection into the dorsal horn of the spinal cord from the nociceptive receptor system is inhibited by the concurrent activity of the mechano receptors located in the same tissues, leads to increased destruction of pain provoking metabolites, such as Lewis's substances. This metabolite, if present in too high concentration, causes ischemia and pain, and also produces the rapeutic movement by breaking down the strong cross links or adhesions that have been formed. Softening the scar tissue and mobilizing the cross links between the mutual collagen fibers and the adhesions between repairing connective tissue and surrounding tissues [40].

Wrist joint splint is used in neutral position to be worn day and nighttime to decrease the pressure on the median nerve and minimize the friction between nerve and all soft tissue around, at the end, improvement of muscle strength and function can be achieved by strengthening exercises [35] [37] [41] [42]. Thus, the improvement of wrist flexion and extension ROM occurred consequently with pain reduction, but no improvement in hand grip due to shortening of the flexor muscles of fingers.

Some authors revealed that physical therapy treatment either ultrasonic, strengthening exercises, or wrist splint are only effective in relieving pain in the management of carpal tunnel syndrome. Although, some of them showed that the electrotherapy, ultrasonic, phonophoresis, iontophoresis and strengthening exercises more effective in the management of CTS [21] [43]. In comparison of results in both groups, there was a significant difference between ROM of wrist flexion and extension, and hand grip in stretching group (longitudinal gliding) than deep transverse friction massage group (transverse gliding) because of increasing the length and power of the muscles which may be acting freely during wrist flexion and extension, and hand grip. However, there was no significant difference for pain in stretching group than deep transverse friction massage group because both groups was sharing same action of decreasing the inflammation and softening of the hard tissues [41].

Significant results of the longitudinal stretching of muscles and nerve group more than the deep transverse friction massage group in pain, ROM of wrist flexion and extension, and hand grip, because in the stretching 
group, there were decreasing the inflammation and softening of the hard adhesive tissues, mobilizing the median nerve inside the carpal tunnel at wrist joint, and increasing the ROM of flexion and extension of the wrist joint and strength of hand grip through stretching exercise. But in the deep transverse friction massage group, there were decreasing the inflammation and softening of the hard adhesive tissues in the carpal tunnel at wrist joint without longitudinal mobilizing of the median nerve inside the tunnel and also shortening of the flexor muscles [41] [42]. This revealed that physical therapy treatment either stretching exercise, ultrasonic, strengthening exercises, and wrist splint are effective in relieving pain in the management of carpal tunnel syndrome. The results of this study come in agreement with many previous findings [21] [42].

This study has several limitations such as the small sample size, using ultrasound and splinting in both groups, which may lead to further clinical improvement in both groups. Further studies should be done on translating and validating CTS patients' reported outcomes, questionnaire into Arabic language and focusing on exercise and deep transfer friction massage only in the management of patients with CTS.

\section{Conclusion}

This study showed that the longitudinal stretching of muscles and nerve in addition to Ultrasound therapy, strengthening exercise, and splinting is more effective than deep transverse friction massage in addition to Ultrasound therapy, strengthening exercise, and splinting in the treatment of patients with carpal tunnel syndrome.

\section{Conflict of Interest}

All authors have no conflict of interest to declare in this study.

\section{References}

[1] Mackinnon, S.E., Novak, C.B. and Green, D.P. (2010) Compression Neuropathies. In: Green’s Operative Hand Surgery, Elsevier, Philadelphia, 977-1015.

[2] Caetano, E. (2010) Bases Anatômicas e Funcionais das Cirurgias do Membro Superior. Medbook, Rio de Janeiro.

[3] Aroori, S. and Spence, R.A. (2008) Carpal Tunnel Syndrome. The Ulster Medical Journal, 77, 6-17.

[4] Okamura, A., et al. (2014) Evaluation of Patients with Carpal Tunnel Syndrome Treated by Endoscopic Technique. Acta Ortopédica Brasileira, 22, 29-33. http://dx.doi.org/10.1590/S1413-78522014000100005

[5] Atroshi, I., et al. (1999) Prevalence of Carpal Tunnel Syndrome in a General Population. JAMA, 282, 153-158. http://dx.doi.org/10.1001/jama.282.2.153

[6] Samarakoon, L.B., et al. (2014) Anatomical Landmarks for Safer Carpal Tunnel Decompression: An Experimental Cadaveric Study. Patient Safety in Surgery, 8, 8. http://dx.doi.org/10.1186/1754-9493-8-8

[7] Ahn, D.S. (2001) Hand Elevation: A New Test for Carpal Tunnel Syndrome. Annals of Plastic Surgery, 46, $120-124$. http://dx.doi.org/10.1097/00000637-200102000-00005

[8] Gellman, H., et al. (1986) Carpal Tunnel Syndrome. An Evaluation of the Provocative Diagnostic Tests. Journal of Bone and Joint Surgery (America Volume), 68, 735-737.

[9] Jenkins, P.J., et al. (2012) Corticosteroid Injection for Carpal Tunnel Syndrome: A 5-Year Survivorship Analysis. Hand, 7, 151-156. http://dx.doi.org/10.1007/s11552-012-9390-8

[10] Marshall, S., Tardif, G. and Ashworth, N. (2007) Local Corticosteroid Injection for Carpal Tunnel Syndrome. Cochrane Database of Systematic Reviews, 2, Article ID: Cd001554.

[11] Jerosch-Herold, C., Shepstone, L., Wilson, E.C.F., Dyer, T. and Blake, J. (2014) Clinical Course, Costs and Predictive Factors for Response to Treatment in Carpal Tunnel Syndrome: The PALMS Study Protocol. BMC Musculoskeletal Disorders, 15, 35. http://dx.doi.org/10.1186/1471-2474-15-35

[12] Gooch, C.L. and Mitten, D.J. (2005) Treatment of Carpal Tunnel Syndrome: Is There a Role for Local Corticosteroid Injection? Neurology, 64, 2006-2007. http://dx.doi.org/10.1212/01.WNL.0000165955.65091.C9

[13] Huisstede, B.M., Randsdorp, M.S., Henk Coert, J., Glerum, S., van Middelkoop, M. and Koes, B.W. (2010) Carpal Tunnel Syndrome. Part II: Effectiveness of Surgical Treatments-A Systematic Review. Archives of Physical Medicine and Rehabilitation, 91, 1005-1024. http://dx.doi.org/10.1016/j.apmr.2010.03.023

[14] Ucar, B.Y., Demirtaş, A., Bulut, M., Azboy, I. and Uçar, D. (2012) Carpal Tunnel Decompression: Two Different Mini-Incision Techniques. European Review for Medical and Pharmacological Sciences, 16, 533-538.

[15] Acioly, M.A., Maior, P.S., Telles, C. and de Aguiar, G.B. (2013) Bilateral Mini-Open Decompression in the Treatment 
of Carpal Tunnel Syndrome Caused by Persistent Median Artery: Case Report. Journal of Neurological Surgery. Part A, Central European Neurosurgery, 74, e124-e127.

[16] Verdugo, R.J., et al. (2008) Surgical versus Non-Surgical Treatment for Carpal Tunnel Syndrome. Cochrane Database Syst Rev, 4, p. Cd001552.

[17] MacDonald, R.I., Lichtman, D.M., Hanlon, J.J. and Wilson, J.N. (1978) Complications of Surgical Release for Carpal Tunnel Syndrome. Journal of Hand Surgery, 3, 70-76. http://dx.doi.org/10.1016/S0363-5023(78)80118-X

[18] Bland, J.D. (2007) Treatment of Carpal Tunnel Syndrome. Muscle \& Nerve, 36, 167-171. http://dx.doi.org/10.1002/mus.20802

[19] Bakhtiary, A.H. and Rashidy-Pour, A. (2004) Ultrasound and Laser Therapy in the Treatment of Carpal Tunnel Syndrome. Australian Journal of Physiotherapy, 50, 147-151. http://dx.doi.org/10.1016/S0004-9514(14)60152-5

[20] Burke, F.D., Ellis, J., McKenna, H. and Bradley, M.J. (2003) Primary Care Management of Carpal Tunnel Syndrome. Postgraduate Medical Journal, 79, 433-437. http://dx.doi.org/10.1136/pmj.79.934.433

[21] Dakowicz, A. and Latosiewicz, R. (2005) The Value of Iontophoresis Combined with Ultrasound in Patients with the Carpal Tunnel Syndrome. Roczniki Akademii Medycznej w Białymstoku, 50, 196-198.

[22] Hayward, A.C., Bradley, M.J. and Burke, F.D. (2002) Primary Care Referral Protocol for Carpal Tunnel Syndrome. Postgraduate Medical Journal, 78, 149-152. http://dx.doi.org/10.1136/pmj.78.917.149

[23] Toge, Y., Nishimura, Y., Basford, J.R., Nogawa, T., Yamanaka, M., Nakamura, T., Yoshida, M., Nagano, A. and Tajima, F. (2013) Comparison of the Effects of Flexion and Extension of the Thumb and Fingers on the Position and Cross-Sectional Area of the Median Nerve. PLOS ONE, 8, e83565. http://dx.doi.org/10.1371/journal.pone.0083565

[24] Gelberman, R.H., Hergenroeder, P.T., Hargens, A.R., Lundborg, G.N. and Akeson, W.H. (1981) The Carpal Tunnel Syndrome. A Study of Carpal Canal Pressures. Journal of Bone and Joint Surgery. American Volume, 63, 380-383.

[25] Lam, N. and Thurston, A. (1998) Association of Obesity, Gender, Age and Occupation with Carpal Tunnel Syndrome. Australian and New Zealand Journal of Surgery, 68, 190-193. http://dx.doi.org/10.1111/j.1445-2197.1998.tb04743.x

[26] Rempel, D., Manojlovic, R., Levinsohn, D.G., Bloom, T. and Gordon, L. (1994) The Effect of Wearing a Flexible Wrist Splint on Carpal Tunnel Pressure during Repetitive Hand Activity. Journal of Hand Surgery, 19, 106-110. http://dx.doi.org/10.1016/0363-5023(94)90231-3

[27] Gerritsen, A.A., de Vet, H.C.W., Scholten, R.J.P.M., Bertelsmann, F.W., de Krom, M.C.T.F.M. and Bouter, L.M. (2002) Splinting vs Surgery in the Treatment of Carpal Tunnel Syndrome: A Randomized Controlled Trial. JAMA, 288, 1245-1251. http://dx.doi.org/10.1001/jama.288.10.1245

[28] Gajdosik, R.L. and Bohannon, R.W. (1987) Clinical Measurement of Range of Motion. Review of Goniometry Emphasizing Reliability and Validity. Physical Therapy, 67, 1867-1872.

[29] Boonstra, A.M., Schiphorst Preuper, H.R., Reneman, M., Posthumus, J.B. and Stewart, R.E. (2008) Reliability and Validity of the Visual Analogue Scale for Disability in Patients with Chronic Musculoskeletal Pain. International Journal of Rehabilitation Research, 31, 165-169. http://dx.doi.org/10.1097/MRR.0b013e3282fc0f93

[30] Lusardi, M.M. and Bohannon, R.W. (1991) Hand Grip Strength: Comparability of Measurements Obtained with a Jamar Dynamometer and a Modified Sphygmomanometer. Journal of Hand Therapy, 4, 117-122. http://dx.doi.org/10.1016/S0894-1130(12)80226-2

[31] Medicine ACoS (2006) ACSM’s Guidelines for Exercise Testing and Prescription. 7th Edition, Lippincott Williams Wilkins, Baltimore.

[32] Groves, E.J. and Rider, B.A. (1989) A Comparison of Treatment Approaches Used after Carpal Tunnel Release Surgery. American Journal of Occupational Therapy, 43, 398-402. http://dx.doi.org/10.5014/ajot.43.6.398

[33] Povlsen, B., Bashir, M. and Wong, F. (2014) Long-Term Result and Patient Reported Outcome of Wrist Splint Treatment for Carpal Tunnel Syndrome. Journal of Plastic Surgery and Hand Surgery, 48, 175-178. http://dx.doi.org/10.3109/2000656X.2013.837392

[34] Akalin, E., El, Ö., Peker, Ö., Şenocak, Ö., Tamci, Ş., Gülbahar, S., Çakmur, R. and Öncel, S. (2002) Treatment of Carpal Tunnel Syndrome with Nerve and Tendon Gliding Exercises. American Journal of Physical Medicine \& Rehabilitation, 81, 108-113. http://dx.doi.org/10.1097/00002060-200202000-00006

[35] Greening, J., Smart, S., Leary, R., Hall-Craggs, M., O’Hggins, P. and Lynn, B. (1999) Reduced Movement of Median Nerve in Carpal Tunnel during Wrist Flexion in Patients with Non-Specific Arm Pain. Lancet, 354, 217-218. http://dx.doi.org/10.1016/S0140-6736(99)02958-X

[36] Rozmaryn, L.M., Dovelle, S., Rothman, E.R., Gorman, K., Olvey, K.M. and Bartko, J.J. (1998) Nerve and Tendon Gliding Exercises and the Conservative Management of Carpal Tunnel Syndrome. Journal of Hand Therapy, 11, 171179. http://dx.doi.org/10.1016/S0894-1130(98)80035-5 
[37] Wilgis, E.F. and Murphy, R. (1986) The Significance of Longitudinal Excursion in Peripheral Nerves. Hand Clinics, 2, 761-766.

[38] Oztas, O., Turan, B., Bora, I. and Karakaya, M.K. (1998) Ultrasound Therapy Effect in Carpal Tunnel Syndrome. Archives of Physical Medicine and Rehabilitation, 79, 1540-1544. http://dx.doi.org/10.1016/S0003-9993(98)90416-6

[39] Pinar, L., Enhos, A., Ada, S. and Güngör, N. (2005) Can We Use Nerve Gliding Exercises in Women with Carpal Tunnel Syndrome? Advances in Therapy, 22, 467-475. http://dx.doi.org/10.1007/BF02849867

[40] Cobb, T.K., Dalley, B.K., Posteraro, R.H. and Lewis, R.C. (1993) Anatomy of the Flexor Retinaculum. Journal of Hand Surgery, 18, 91-99. http://dx.doi.org/10.1016/0363-5023(93)90251-W

[41] Chamberlain, G.J. (1982) Cyriax’s Friction Massage: A Review. Journal of Orthopaedic \& Sports Physical Therapy, 4, 16-22. http://dx.doi.org/10.2519/jospt.1982.4.1.16

[42] Piravej, K. and Boonhong, J. (2004) Effect of Ultrasound Thermotherapy in Mild to Moderate Carpal Tunnel Syndrome. Journal of the Medical Association of Thailand, 87, S100-S1006.

[43] Lee, D., van Holsbeeck, M.T., Janevski, P.K., Ganos, D.L., Ditmars, D.M. and Darian, V.B. (1999) Diagnosis of Carpal Tunnel Syndrome. Ultrasound versus Electromyography. Radiologic Clinics of North America, 37, 859-872. http://dx.doi.org/10.1016/S0033-8389(05)70132-9 
Scientific Research Publishing (SCIRP) is one of the largest Open Access journal publishers. It is currently publishing more than 200 open access, online, peer-reviewed journals covering a wide range of academic disciplines. SCIRP serves the worldwide academic communities and contributes to the progress and application of science with its publication.

Other selected journals from SCIRP are listed as below. Submit your manuscript to us via either submit@scirp.org or Online Submission Portal.
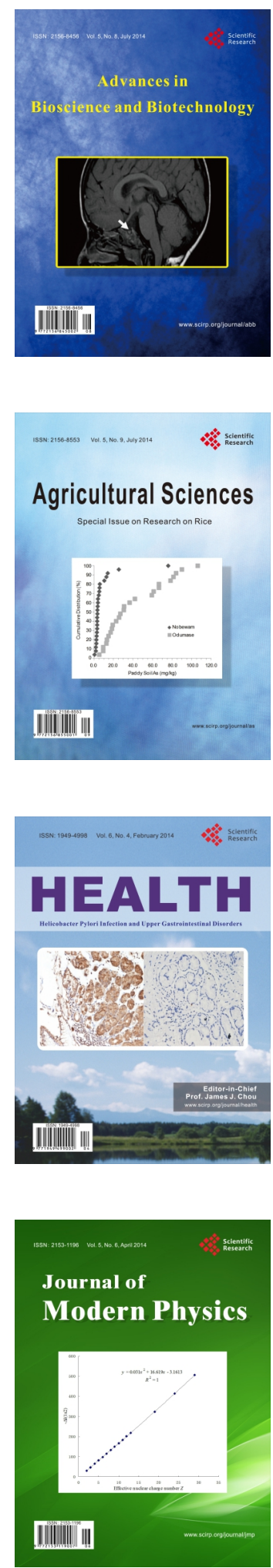
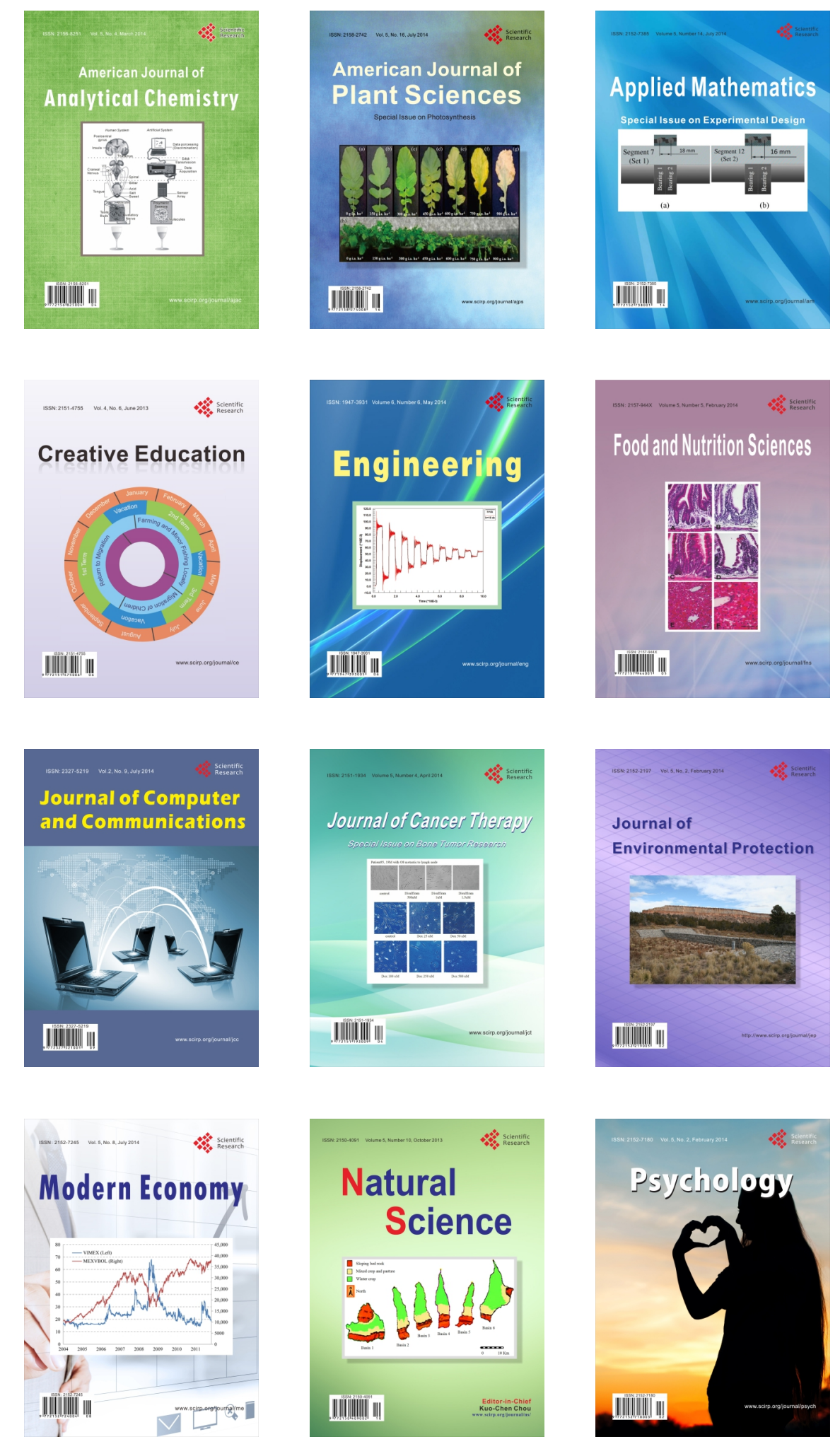